\title{
Knowledge of Cervical Cancer and Associated Factors Among Women Attending Public Health Facilities in Eastern Ethiopia
}

This article was published in the following Dove Press journal: Cancer Management and Research

\author{
Elias Bekele Wakwoya (iD) \\ Kasiye Shiferaw Gemechu ${ }^{2}$ \\ Tamirat Tesfaye Dasa (iD ${ }^{3}$ \\ 'College of Health Sciences, Department \\ of Midwifery, Arsi University, Asella, \\ Ethiopia; ${ }^{2}$ College of Health and Medical \\ Sciences, Department of Midwifery, \\ Haramaya University, Harar, Ethiopia; \\ ${ }^{3}$ College of Medicine and Health \\ Sciences, Department of Midwifery, \\ Hawassa University, Hawassa, Ethiopia
}

Purpose: This study was done to assess women's knowledge of cervical cancer and associated factors.

Materials and Methods: We conducted a facility-based cross-sectional study in eastern Ethiopia from January 1 to May 30, 2019. A convenient sampling technique was used to include 1181 women in this study. Information on socio-demographic characteristics, sexual history, knowledge and awareness of women was collected using face-to-face interview. The data were cleaned, coded and entered into EPI-info version 3.5.4 and then exported to Statistical Package for Social Science version 23.0 software for analysis. The associations between independent variables and outcome variables were assessed using bivariate and multivariable logistic regressions. The results of these analyses were reported as odds ratios with $95 \%$ confidence intervals. We declared statistically significant variables at a $p$-value less than 0.05 .

Results: Nearly half $(574,48.6 \%)$ of the participants have ever heard about cervical cancer. One hundred and thirty-nine $(24.2 \%)$ of them did not know any of the risk factors. The majority of them mentioned bleeding after intercourse $(329,57.4 \%)$ as a symptom of the disease. Overall knowledge assessment revealed that 288 (55.7\%) participants had adequate knowledge about cervical cancer. Participants' age in the range of 40-49 years (AOR: 2.58, 95\% CI 1.99-5.57), having educational level above 12th grade (AOR: 12.11, 95\% CI 4.57-32.09) and receiving information about the disease from healthcare professionals (AOR: 2.72, 95\% CI 1.69-4.37) were independently associated with adequate knowledge of cervical cancer.

Conclusion: The knowledge of women towards cervical cancer in our study area was inadequate. The respondents' age, educational status and source of information were independently associated with study participants' knowledge of cervical cancer. Young women with no formal education should get special focus in prevention strategies and we also recommend regular and effective counselling, and education about cervical cancer at health institutions.

Keywords: cervical cancer, knowledge, associated factors, Ethiopia

\section{Introduction}

Cervical cancer is the fourth most common cancer among women after breast, colorectal and lung cancers. It is well proved that cervical cancer is the most preventable and curable disease if detected and treated early. However, in many developing countries cervical cancer continues to be the common cause of death among women between 25 and 49 years of age. According to the world statistics report in 2018, globally there
Correspondence: Elias Bekele Wakwoya College of Health Sciences, Department of Midwifery, Arsi University, Postal Address: 04, Asella, Ethiopia Tel +25191307042I

Email eliasbekele2020@arsiun.edu.et
Cancer Management and Research 2020:12 10103-101II

10103 
were 570,000 new cases of cervical cancer and 311,365 deaths due to this disease. Eastern Africa is among the severely affected regions by cervical cancer with 52,633 new cases and 37,017 deaths annually. ${ }^{1-3}$

Ethiopia has a population of 29.4 million women who are at risk of developing cervical cancer. In Ethiopia, cervical cancer was the second most frequent cancer among women between 15 and 44 years of age and 6,294 women were diagnosed with cervical cancer and 4,884 died of this disease. An absence of prevention strategies is the main obstacle to cervical cancer prevention and control in developing countries. ${ }^{4-7}$ It is evidenced that knowledge of cervical cancer affects cervical cancer screening uptake in different countries. Women who have adequate knowledge utilize the service more than women who have inadequate knowledge about cervical cancer. ${ }^{8,9}$

Women's knowledge of cervical cancer in sub-Saharan African countries is low as compared to other regions of the world. ${ }^{10,11}$ Different studies also revealed that knowledge of women about cervical cancer is very low in Ethiopia. ${ }^{12-16}$ The majority of respondents in previous studies have heard about cervical cancer, but not more than half of respondents know what causes cervical cancer and the risk factors associated with the disease. ${ }^{17,18}$ Women's age, marital status, occupation, educational status, source of information, knowing someone with cervical cancer and health-seeking behavior were found to be associated with cervical cancer knowledge in Ethiopia. ${ }^{19-22}$ However, none of these studies have assessed the association of HIV status and using family planning methods with the knowledge of cervical cancer.

Cervical cancer screening is extremely low in Ethiopia and the Harari region is at the bottom line with only $2.2 \%$ of eligible women screened. ${ }^{23}$ As knowledge about cervical cancer is an important factor for practising the screening, it would be crucial to identify the knowledge and associated factors. Therefore, this study aims to fill that by providing evidence on the level of knowledge of cervical cancer and associated factors among women in Harar city, eastern Ethiopia. Additionally, the study was done to measure the association of those factors which were not addressed by previous studies in Ethiopia. The output of this study provided evidence-based information to the hospital administrations, Harari regional health bureau and nongovernmental organizations to exert a maximum effort to improve cervical cancer knowledge and screening utilization.

\section{Materials and Methods}

\section{Study Design, Study Area and Period}

The study was a descriptive cross-sectional study conducted among women attending gynecology OPD (Out Patient Department), ART (Anti-Retroviral Therapy) clinic and family planning units in two public hospitals in Harar city, eastern part of Ethiopia. Hiwot Fana Specialized University Hospital (HFSUH) is a teaching referral hospital of Haramaya University with 900-bed capacity that has been delivering healthcare services to Harari region and its surrounding population. Jugal Hospital is a regional referral hospital of the Harari National Regional State. A cervical cancer screening service was launched in 2016 in both hospitals. This study was conducted from January 1 to May 30, 2019.

\section{Study Participants, Sample Size and Sampling Procedure}

All women between 25 and 49 years of age attending the selected outpatient clinics of either hospital during the study period were included in the study. Critically ill patients who did not give informed consent were excluded from the study. The minimum sample size was calculated by using a single population proportion formula, $n=Z^{2} p(1-p) / d^{2}$ with assumptions of margin of error $3 \%(\mathrm{~d}=0.03)$, standard error corresponding to $95 \%$ confidence interval level $(Z=1.96)$ and the proportion of women who were knowledgeable about cervical cancer from a previous study (p) of $43.8 \% .{ }^{17}$ The calculated sample size was 1051 and after adjusting for a non-response rate of $10 \%$, the final sample size was 1157 women. We have also calculated the sample size for the analytical part of this study. This article is part of a project and we used the maximum sample size calculated among the objectives of this project, which was 1240 women. The sample size was allocated proportionally based on the size of the case-load to each hospital. A serial (convenient) sampling technique was used to recruit study participants.

\section{Data Collection}

A structured and pretested questionnaire was used to collect information on socio-demographic characteristics, sexual history and knowledge of women. Following the verbal consent, an exit interview was conducted by trained bachelor degree nurses and midwives who were not employed in either of the hospitals. The knowledge questions were adopted from previous studies and a total of 14 questions (4 risk factors related, 6 symptoms related and 4 prevention related questions) 
were presented to study participants. ${ }^{24,25}$ We adopted a similar scoring system from another study to assess cervical cancer knowledge. ${ }^{20}$ Score one was assigned if the risk factors, symptoms and prevention methods were correctly identified by the respondents. On the other hand, a score of zero was given if the respondent answers the incorrect or "I don't know" response. The maximum score for the total knowledge questions was 14 and respondents with an average score of greater than seven $(>7)$ were categorized as having adequate knowledge of cervical cancer, while respondents with a score less than or equal to seven $(\leq 7)$ were categorized as having inadequate knowledge. The reliability of items was evaluated by using Cronbach's alpha, and in the present study Cronbach's alpha was 0.78 which indicates good internal consistency. This study was conducted in accordance with the Declaration of Helsinki and it was approved by the Haramaya University institutional health research ethics review committee. Written and signed informed consent were obtained from each study participant and head of both hospitals prior to interview. The data collection procedure was anonymous in order to keep the confidentiality of any information provided by the study participants.

\section{Data Analysis}

The collected data were entered into EPI-info version 3.5.4 and then exported to SPSS (Statistical Package for Social Science) version 23.0 software for analysis. Descriptive statistics like frequencies, percentages and crosstabulations were done. Binary logistic regressions were used to check associations of independent variables and outcome variables. Variables with $p$-values $\leq 0.2$ in bivariate analysis were retained in the model as potential confounders for multivariable analysis. Hosmer and Lemeshow's goodness-of-fit test was performed to assess whether the required assumption was fulfilled and variance inflation factors were low $(<10)$ for the multi-collinearity check. An adjusted odds ratio with $95 \%$ confidence intervals and a $p$-value less than 0.05 were considered a statistically significant association with the women's knowledge of cervical cancer.

\section{Results}

\section{Socio-Demographic Characteristics of Respondents}

Out of 1240 participants approached, 1181 of them responded to our study making a $95.2 \%$ response rate.
The majority of the respondents were; married 948 (80.3\%), Muslims 702 (59.4\%) and Oromo ethnic group 706 (59.8\%). The mean age of the respondents was 32.50 ( $\mathrm{SD} \pm 6.35)$ years. The greater proportion $(398,33.7 \%$ ) of the respondents were unable to read and write, followed by those who attended primary education $(382,32.3 \%)$. More than two-thirds of study participants $(821,69.5 \%)$ were from urban areas while $360(30.5 \%)$ were from rural areas (Table 1).

\section{Reproductive History of Respondents}

The majority of respondents $(975,82.6 \%)$ gave birth to a child at least once, and of these two-thirds $(645,66.2 \%)$ had 1-3 babies. One-fourth of the respondents $(295,25 \%)$ and 347 (29.4\%) of their partners had a history of sexual intercourse with more than one person. Ninety-one (7.7\%) of the respondents were diagnosed with sexually transmitted infections (STI) while $68(5.8 \%)$ of their partners were ever diagnosed with STI. More than half of the respondents $(54.8 \%)$ had ever used modern FP methods, and injectable $(264,41 \%)$ and implants $(248,38.3 \%)$ were the commonly used methods. The study participants used FP methods for a mean duration of 33.85 months (Table 2).

\section{Women's Knowledge of Cervical Cancer}

Five hundred and seventy-four (48.6\%) of the study participants have ever heard about cervical cancer. The majority of them heard about the disease for the first time from mass media (radio and television) whereas onefourth of them $(148,25.8 \%)$ got the information from healthcare professionals. Among respondents who heard about cervical cancer, 139 (24.2\%) did not know any risk factors, $65(11.3 \%)$ knew at least one risk factor and 139 (24.2\%) answered all risk factors associated with cervical cancer. On the other hand, $415(72.3 \%)$ of respondents mentioned having multiple sexual partners is a risk factor for acquiring cervical cancer. The greater proportion (267, $46.5 \%$ ) of respondents did not know whether family history could be a risk factor for acquiring cervical cancer (Table 3).

The majority of the study participants $(83.3 \%)$ knew at least one symptom associated with cervical cancer. About $108(18.8 \%)$ respondents answered all of the symptoms mentioned in the questionnaire while $16.7 \%$ of the respondents did not know any of the listed symptoms. The majority of the respondents mentioned bleeding after intercourse $(329,57.4 \%)$ and irregular menstrual bleeding 
Table I Socio-Demographic Characteristics of Respondents at HFSUH and Jugal Hospital, January I to May 30, 2019

\begin{tabular}{|c|c|c|c|}
\hline $\begin{array}{l}\text { Variables } \\
(\mathrm{N}=|| 8 \mid)\end{array}$ & Category & Frequency & $\begin{array}{l}\text { Percentage } \\
\text { (\%) }\end{array}$ \\
\hline \multirow[t]{4}{*}{ Age } & $25-29$ & 625 & 52.9 \\
\hline & $30-34$ & 241 & 20.4 \\
\hline & $35-39$ & 199 & 16.9 \\
\hline & $40-49$ & 116 & 9.8 \\
\hline \multirow[t]{4}{*}{ Marital status } & Married & 948 & 80.3 \\
\hline & Single & 101 & 8.6 \\
\hline & Divorced & 93 & 7.9 \\
\hline & Widowed & 39 & 3.3 \\
\hline \multirow[t]{4}{*}{ Religion } & Muslim & 702 & 59.4 \\
\hline & Orthodox & 372 & 31.5 \\
\hline & Protestant & 99 & 8.4 \\
\hline & Others & 8 & 0.7 \\
\hline \multirow[t]{5}{*}{ Ethnicity } & Oromo & 706 & 59.8 \\
\hline & Amhara & 335 & 28.4 \\
\hline & Harari & 78 & 6.6 \\
\hline & Tigray & 11 & 0.9 \\
\hline & Others & 51 & 4.3 \\
\hline \multirow[t]{6}{*}{ Occupation } & Housewife & 573 & 48.5 \\
\hline & Self-employees & 186 & 15.7 \\
\hline & $\begin{array}{l}\text { Government } \\
\text { employees }\end{array}$ & 202 & I7.I \\
\hline & Daily labourer & 46 & 3.9 \\
\hline & Merchant & 123 & 10.4 \\
\hline & Others & 51 & 4.3 \\
\hline \multirow[t]{4}{*}{$\begin{array}{l}\text { Educational } \\
\text { status }\end{array}$} & $\begin{array}{l}\text { Unable to read and } \\
\text { write }\end{array}$ & 398 & \\
\hline & $\begin{array}{l}\text { Primary education } \\
(\mathrm{I}-8)\end{array}$ & 382 & 32.3 \\
\hline & $\begin{array}{l}\text { Secondary } \\
\text { education }(9-10 \\
+2)\end{array}$ & 234 & 19.8 \\
\hline & $\begin{array}{l}\text { I } 2 \text { complete and } \\
\text { above }\end{array}$ & 167 & 14.1 \\
\hline \multirow[t]{2}{*}{ Residence } & Urban & 821 & 69.5 \\
\hline & Rural & 360 & 30.5 \\
\hline
\end{tabular}

(331, 57.7\%) as the symptoms of cervical cancer. About $326(56.8 \%)$ of the study participants knew that a woman can have cervical cancer without manifesting symptoms (Table 3). Sixty per cent of study participants knew a precancerous cervical lesion screening service is available in Harar city. Overall knowledge assessment revealed, out of those who heard about cervical cancer, 288 (55.7\%) of study participants had adequate knowledge about cervical cancer (Figure 1).
Table 2 Reproductive History of Participants of Respondents at HFSUH and Jugal Hospital, January I to May 30, 2019

\begin{tabular}{|l|l|l|l|}
\hline Variables (N = I I 8 I) & Category & Frequency & $\begin{array}{l}\text { Percentage } \\
\text { (\%) }\end{array}$ \\
\hline Ever delivered baby & $\begin{array}{l}\text { Yes } \\
\text { No }\end{array}$ & $\begin{array}{l}975 \\
206\end{array}$ & $\begin{array}{l}82.6 \\
17.4\end{array}$ \\
\hline Number of deliveries & I-3 & 645 & 66.2 \\
& $4-7$ & 277 & 28.4 \\
8 and & 53 & 5.4 \\
\hline above & & \\
\hline Number of alive babies & $0-3$ & 706 & 72.4 \\
& $4-7$ & 236 & 24.2 \\
& 8 and & 33 & 3.4 \\
\hline History of multiple & Yes & 295 & 25.0 \\
sexual partners & No & 886 & 75.0 \\
\hline History of partner's & Yes & 347 & 29.4 \\
multiple sexual & No & 834 & 70.6 \\
partners & & & \\
\hline $\begin{array}{l}\text { Ever diagnosed with } \\
\text { STI }\end{array}$ & Yes & 91 & 7.7 \\
\hline Ever used modern FP & Yes & 647 & 92.3 \\
methods & No & 534 & 45.2 \\
\hline
\end{tabular}

\section{Factors Associated with Women's Knowledge of Cervical Cancer}

Table 4 summarizes bivariate logistic regression analysis of socio-demographic and other characteristics of study participants that associated with women's knowledge of cervical cancer. Among those variables, older age, increased educational status, being an employee, living in an urban area, previously not using family planning methods and receiving information about cervical cancer from health professionals were positively associated with women's cervical cancer knowledge during bivariate analysis (Table 4). However, during multivariable analysis only women's age, educational status and sources of information had a statistically significant positive association. The study participants whose age was 40-49 years had increased odds of adequate knowledge about cervical cancer compared to the age group 25-29 years (AOR: 2.58, 95\% CI 1.99-5.57). Women who have attended primary level education (AOR: 7.07, 95\% CI 3.13-15.95), secondary education (AOR: 7.20, 95\% CI 2.95-17.59) and attained education level above $12^{\text {th }}$ grade (AOR: 12.11, 95\% CI 4.57-32.09) have increased odds of adequate 
Table 3 Identified Risk Factors, Symptoms and Prevention Methods of Cervical Cancer by Respondents at HFSUH and Jugal Hospital, January I to May 30, 2019

\begin{tabular}{|c|c|c|c|}
\hline Variables $(\mathbf{N}=1 \mid 8 I)$ & Yes (\%) & No (\%) & I Do Not Know (\%) \\
\hline Having multiple sexual partner is a risk for cervical cancer & $415(72.3)$ & $10(1.7)$ & $149(26)$ \\
\hline Sexually transmitted infections are a risk for cervical cancer & $353(6 I .5)$ & $59(10.3)$ & $162(28.2)$ \\
\hline Early initiation of sex can be a risk for cervical cancer & $305(53.1)$ & $71(12.4)$ & $198(34.5)$ \\
\hline Family history of abnormal cervical lesion is a risk for cervical cancer & $167(29.1)$ & $140(24.4)$ & $267(46.5)$ \\
\hline Irregular menstrual bleeding is a symptom of cervical cancer & $331(57.7)$ & $5 \mathrm{I}(8.9)$ & $192(33.4)$ \\
\hline Bleeding after sexual intercourse is a symptom of cervical cancer & $329(57.4)$ & $64(11.1)$ & $|8|(3 \mid .5)$ \\
\hline Weight loss is a symptom of cervical cancer & $227(39.5)$ & $101(17.6)$ & $246(42.9)$ \\
\hline Difficulty in passing urine is a symptom of cervical cancer & $252(43.9)$ & $92(16.0)$ & $230(40.1)$ \\
\hline Blood-stained vaginal discharge is a symptom of cervical cancer & $303(52.8)$ & $49(4.1)$ & $222(38.7)$ \\
\hline A woman can have cervical cancer without manifesting symptoms & $326(56.8)$ & $93(16.2)$ & $155(27.0)$ \\
\hline Cervical cancer is a killer if not detected early & $478(83.3)$ & $16(2.8)$ & $80(13.9)$ \\
\hline Screening can prevent advanced cervical cancer & $372(87.9)$ & $21(5.0)$ & $30(7.1)$ \\
\hline All females aged $30-49$ years should be screened at least once & $284(67.1)$ & $38(9.0)$ & $101(23.9)$ \\
\hline Cervical cancer screening services are available in Harar & $255(60.3)$ & $5(1.2)$ & $163(38.5)$ \\
\hline
\end{tabular}

knowledge compared to uneducated women. In addition, there is increased odds of having adequate cervical cancer knowledge among study participants who got information about the disease from healthcare professionals compared to those who got information from mass media (AOR: 2.72, 95\% CI 1.69-4.37) (Table 5).

\section{Discussion}

This study measured knowledge and factors associated with cervical cancer among women attending two public health facilities in eastern Ethiopia. In the current study nearly half of the study participants have ever heard about cervical cancer. This result is lower than similar studies from Uganda (99.1\%), Kenya (91\%) and Bahrain
$(65 \%) .{ }^{25-27}$ The variation might be due to the difference in educational level, with more than one-third of study participants in the current study having no formal education. In this study the main source of information about cervical cancer was mass media (radio or TV) followed by health professionals.

In this study a greater proportion of respondents cited multiple sexual partners as a risk factor for cervical cancer. As it is indicated in different studies, individuals who have adequate knowledge often practise preventive methods and utilize care services more than their counterparts. ${ }^{28}$ Hence, knowledge of women about cervical cancer is an important and forefront factor to prevent the development of cervical cancer. Similarly, multiple

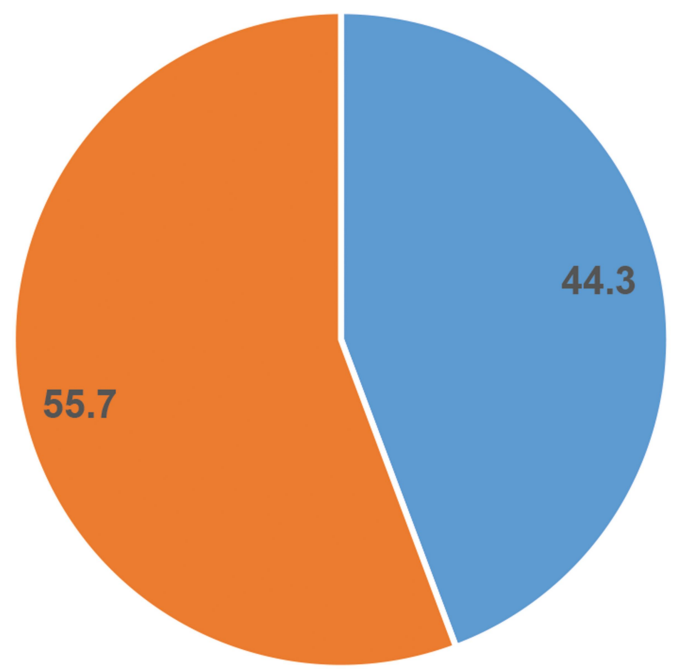

- Inadequate knowledge

- Adequate knowledge

Figure I Comprehensive knowledge about cervical cancer among respondents at HFSUH and Jugal hospital, January I to May $30,2019$. 
Table 4 Bivariate Logistic Regression Analysis of Selected Characteristics of Study Participants and Cervical Cancer Knowledge

\begin{tabular}{|c|c|c|c|c|}
\hline \multirow[t]{2}{*}{ Variables $(\mathbf{N}=|| 8 \mid)$} & \multicolumn{2}{|c|}{ Knowledge of Cervical Cancer } & \multirow[t]{2}{*}{ COR $[95 \% \mathrm{Cl}$} & \multirow[t]{2}{*}{$p$ value } \\
\hline & Inadequate & Adequate & & \\
\hline \multicolumn{5}{|l|}{ Age } \\
\hline $25-29$ & 135 (48.9\%) & $14 \mid(51.1 \%)$ & Ref & \\
\hline $30-34$ & $46(46 \%)$ & $54(54 \%)$ & $1.12[0.71-1.78]$ & 0.618 \\
\hline $35-39$ & $34(35.8 \%)$ & $61(64.2 \%)$ & $1.72[1.06-2.78]$ & 0.028 \\
\hline $40-49$ & $14(30.4 \%)$ & $32(69.6 \%)$ & $2.19[1.12-4.28]$ & 0.022 \\
\hline \multicolumn{5}{|l|}{ Marital status } \\
\hline Married & $172(44.4 \%)$ & $215(55.6 \%)$ & $0.83[0.49-1.42]$ & 0.504 \\
\hline Widowed & $7(41.2 \%)$ & $10(58.8 \%)$ & $0.95[0.32-2.82]$ & 0.930 \\
\hline Divorced & $24(50.0 \%)$ & $24(5 \mathrm{C} 0.0 \%)$ & $0.68[0.31-1.42]$ & 0.291 \\
\hline Single & $26(40 \%)$ & $39(60 \%)$ & Ref & \\
\hline \multicolumn{5}{|l|}{ Educational status } \\
\hline Unable to read and write & $52(83.9 \%)$ & $10(16.1 \%)$ & Ref & \\
\hline Elementary level & $83(43.7 \%)$ & $107(56.3 \%)$ & $6.7[3.21-13.98]$ & 0.001 \\
\hline Secondary education & $64(41.6 \%)$ & $90(58.4 \%)$ & $7.31[3.46-15.46]$ & 0.001 \\
\hline 12 complete and above & $30(27 \%)$ & 81 (73\%) & $14.04[6.33-31.12]$ & 0.001 \\
\hline \multicolumn{5}{|l|}{ Occupation } \\
\hline Housewife & $86(51.8 \%)$ & $80(48.2 \%)$ & Ref & \\
\hline Employee & 76 (34.7\%) & 143 (65.3\%) & $2.02[1.34-3.05]$ & 0.01 \\
\hline Daily labourer & $15(65.2 \%)$ & $8(34.8 \%)$ & $0.57[0.23-1.43]$ & 0.231 \\
\hline Merchant & $4 \mathrm{l}(51.9 \%)$ & 38 (48.1\%) & $0.99[0.58-1.70]$ & 0.989 \\
\hline Others & II (36.7\%) & $19(63.3 \%)$ & $1.86[0.83-4.14]$ & 0.131 \\
\hline \multicolumn{5}{|l|}{ Income } \\
\hline$<1500$ & $40(47.1 \%)$ & 45 (52.9\%) & $0.61[0.33-1.12]$ & 0.210 \\
\hline $1500-5000$ & 157 (46.0\%) & $184(54.0 \%)$ & 0.64 [0.39-I.03] & 0.564 \\
\hline$>5000$ & $32(35.2 \%)$ & 59 (64.8\%) & Ref & \\
\hline \multicolumn{5}{|l|}{ Residence } \\
\hline Rural & $24(66.3 \%)$ & $12(33.7 \%)$ & Ref & \\
\hline Urban & 205 (42.6\%) & $276(57.4 \%)$ & $2.69[|.32-5.5|]$ & 0.007 \\
\hline \multicolumn{5}{|l|}{ Parity } \\
\hline$<2$ & $105(43.6 \%)$ & $136(56.4 \%)$ & Ref & \\
\hline $2-5$ & 77 (50.7\%) & 75 (49.3\%) & $0.75[0.50-1.13]$ & 0.270 \\
\hline$>5$ & $7(33.3 \%)$ & $14(66.7 \%)$ & $1.54[0.60-3.96]$ & 0.366 \\
\hline \multicolumn{5}{|l|}{ HIV status } \\
\hline Negative & $163(43.0 \%)$ & $216(57.0 \%)$ & $1.26[0.78-2.04]$ & 0.348 \\
\hline Positive & 39 (48.8\%) & $4 \mathrm{I}(5 \mathrm{I} .2 \%)$ & Ref & \\
\hline \multicolumn{5}{|l|}{ Family planning use } \\
\hline No & 64 (37.9\%) & $105(62.1 \%)$ & Ref & \\
\hline Yes & 165 (47.4\%) & $183(52.6 \%)$ & $1.48[1.02-2.15]$ & 0.04 \\
\hline \multicolumn{5}{|l|}{ Source of information } \\
\hline Mass media & 157 (49.1\%) & $163(50.9 \%)$ & Ref & \\
\hline Health professionals & 44 (30.8\%) & 99 (69.2\%) & $2.17[1.43-3.29]$ & 0.001 \\
\hline Friends/neighbour & $28(51.9 \%)$ & $26(48.1 \%)$ & $0.89[0.50-1.59]$ & 0.705 \\
\hline
\end{tabular}


Table 5 Multivariate Logistic Regression Analysis of Selected Characteristics of Study Participants and Cervical Cancer Knowledge

\begin{tabular}{|c|c|c|c|c|}
\hline \multirow[t]{2}{*}{ Variables } & \multicolumn{2}{|c|}{ Knowledge of Cervical Cancer } & \multirow[t]{2}{*}{ AOR $[95 \% \mathrm{Cl}]$} & \multirow[t]{2}{*}{$p$ value } \\
\hline & Inadequate & Adequate & & \\
\hline \multicolumn{5}{|l|}{ Age } \\
\hline $25-29$ & I 35 (48.9\%) & $14 \mid(5 \mid .1 \%)$ & Ref & \\
\hline $30-34$ & $46(46 \%)$ & $54(54 \%)$ & $1.16[0.70-1.93]$ & 0.562 \\
\hline $35-39$ & $34(35.8 \%)$ & $61(64.2 \%)$ & $1.77[1.03-3.02]$ & 0.038 \\
\hline $40-49$ & $14(30.4 \%)$ & $32(69.6 \%)$ & $2.58[1.99-5.57]$ & 0.015 \\
\hline \multicolumn{5}{|l|}{ Educational status } \\
\hline Unable to read and write & 52 (83.9\%) & $10(16.1 \%)$ & Ref & \\
\hline Elementary level & $83(43.7 \%)$ & $107(56.3 \%)$ & $7.07[3.13-15.95]$ & 0.001 \\
\hline Secondary education & $64(41.6 \%)$ & $90(58.4 \%)$ & $7.20[2.95-17.59]$ & 0.001 \\
\hline 12 complete and above & $30(27 \%)$ & 81 (73\%) & 12.11 [4.57-32.09] & 0.001 \\
\hline \multicolumn{5}{|l|}{ Occupation } \\
\hline Housewife & $86(51.8 \%)$ & $80(48.2 \%)$ & Ref & \\
\hline Employee & $76(34.7 \%)$ & $143(65.3 \%)$ & $1.12[0.64-1.93]$ & 0.697 \\
\hline Daily labourer & $15(65.2 \%)$ & $8(34.8 \%)$ & $0.52[0.18-1.51]$ & 0.227 \\
\hline Merchant & 41 (5I.9\%) & $38(48.1 \%)$ & $0.99[0.55-1.80]$ & 0.997 \\
\hline Others & II (36.7\%) & $19(63.3 \%)$ & $1.45[0.57-3.68]$ & 0.438 \\
\hline \multicolumn{5}{|l|}{ Residence } \\
\hline Rural & $24(66.3 \%)$ & $12(33.7 \%)$ & Ref & \\
\hline Urban & $205(42.6 \%)$ & $276(57.4 \%)$ & $1.38[0.58-3.28]$ & 0.461 \\
\hline \multicolumn{5}{|l|}{ Family planning use } \\
\hline No & $64(37.9 \%)$ & $105(62.1 \%)$ & Ref & \\
\hline Yes & $165(47.4 \%)$ & I83 (52.6\%) & $0.84[0.55-1.27]$ & 0.396 \\
\hline \multicolumn{5}{|l|}{ Source of information } \\
\hline Mass media & 157 (49.1\%) & $163(50.9 \%)$ & Ref & \\
\hline Health professionals & $44(30.8 \%)$ & $99(69.2 \%)$ & $2.72[1.69-4.37]$ & 0.001 \\
\hline Friends/neighbour & $28(51.9 \%)$ & $26(48.1 \%)$ & $1.00[0.54-1.86]$ & 0.997 \\
\hline
\end{tabular}

sexual partners is a frequently cited risk factor in the studies from eastern Uganda and Qatar. ${ }^{29,30}$

Knowing the symptoms of cervical cancer helps women to seek healthcare early and get treatment before it gets worse. The majority of respondents in this study mentioned bleeding after sexual intercourse and irregular menstrual cycles as the symptoms of cervical cancer. Similarly, intermenstrual and post-coital bleeding were mentioned as symptoms of cervical cancer in the study done in northern Uganda. ${ }^{25}$

In the present study $55.7 \%$ of participants had adequate knowledge about cervical cancer. This finding is in line with the report of the study done in southern Ethiopia. ${ }^{18}$ However, it is higher than the reports of a similar study done in western and northern parts of Ethiopia. ${ }^{12,16}$ This discrepancy might be due to the majority of participants in this study being from urban areas who may have a higher opportunity of getting information about cervical cancer from mass media and other sources.

Women's age, educational status and source of information were factors significantly and independently associated with cervical cancer knowledge when adjusted for the effect of other factors in multivariable logistic regression analysis. In the current study, having formal education was positively associated with women's cervical cancer knowledge. As the educational level increases, the odds of having adequate cervical cancer knowledge increases among the study population. This finding is in accordance with other studies done in Ethiopia and other countries. ${ }^{20,22,31}$ The increment of knowledge of cervical cancer with educational level indicates educated women have better information-absorbing ability and understanding. This suggests that all women 
must get at least access to primary education as this can increase their knowledge about cervical cancer.

In the current study the odds of adequate cervical cancer knowledge was higher among women whose age was between 40 and 49 years. This finding is consistent with the study done in Bhopal, India. ${ }^{32}$ This can be explained as younger women usually appear to be healthy and have less frequent contacts with healthcare professionals. This might decrease the chance of young women getting information from healthcare providers, as they are the major source of information for cervical cancer in our study.

Receiving relevant information regarding cervical cancer from healthcare providers has been shown to positively affect knowledge of participants. In this study, women who received information about cervical cancer from healthcare professionals had higher odds of adequate knowledge about cervical cancer. This result is also supported by the finding of a study done in southern California. ${ }^{33}$ The information provided by healthcare providers is accurate and correct as compared to other sources of information. In addition, improving the knowledge of women about cervical cancer discussion with healthcare professionals helps to correct misconceptions and rumours about cervical cancer screening.

The limitation of this study is the fact that since the study design was a cross-sectional study, temporal relations could not be established. In addition to this, since it is facility-based study and included participants only from selected health institutions, it does not consider women who did not visit the health facilities. This might affect the representatives of our findings to Harar town. Information (recall) bias and social desirability bias might have also affected our study. Regardless of these limitations, our findings have implications for health professionals, hospital administrations, health offices and policy-makers.

\section{Conclusion}

The knowledge of women towards cervical cancer in our study area was inadequate. Women's age, educational status and source of information were independently associated with cervical cancer knowledge in multivariable logistic regression analysis. Young women with no formal education should get special focus in prevention strategies and we also recommend regular and effective counselling and education about cervical cancer in health institutions.

\section{Data Sharing Statement}

Data can be provided for all interested persons upon request from the principal investigator.

\section{Ethics Approval and Informed Consent}

This study was conducted in accordance with the Declaration of Helsinki and it was approved by the Haramaya University institutional health research ethics review committee and the approval number was (COHMS/10.0/2968/18). A letter of cooperation was written from Haramaya University, college of health and medical sciences to both hospitals. The objectives and purposes of the studies, as well as risks and benefits were explained to the participants according to the level of their understanding. Participants were informed that participation in the study is voluntary; they have the right to withdraw or refuse to participate in the study at any time. Written and signed informed consent were obtained from each study participant and head of both hospitals prior to interview as it is stated in the participant information sheet. The data collection procedure was anonymous in order to keep the confidentiality of any information provided by the study participants.

\section{Acknowledgments}

The authors would like to acknowledge the Center for International Reproductive Health Training (CIRHT) for funding this study and Haramaya University for its technical support during the study time.

\section{Funding}

Center for International Reproductive Health Training (CIRHT) funded this research.

\section{Disclosure}

All the authors declare that they have no competing interests in this work.

\section{References}

1. Arbyn M, Weiderpass E, Bruni L, et al. Estimates of incidence and mortality of cervical cancer in 2018: a worldwide analysis. The Lancet Global Health. 2020;8(2):. doi:10.1016/S2214-109X(19)30482-6

2. Bray F, Ferlay J, Soerjomataram I, Siegel RL, Torre LA, Jemal A. Global cancer statistics 2018: GLOBOCAN estimates of incidence and mortality worldwide for 36 cancers in 185 countries. CA Cancer J Clin. 2018;68(6):394-424.

3. Ferlay J, Colombet M, Soerjomataram I, et al. Estimating the global cancer incidence and mortality in 2018: GLOBOCAN sources and methods. Int J Cancer. 2019;144(8):1941-1953. doi:10.1002/ijc.31937 
4. Ntekim A. Cervical cancer in sub Sahara Africa. In: R. Rajamanickam, editor. Topics on Cervical Cancer with an Advocacy for Prevention. Intech. 2012:51.

5. Birhanu Z, Abdissa A, Belachew T, et al. Health seeking behavior for cervical cancer in Ethiopia: a qualitative study. Int $J$ Equity Health. 2012;11(1):83. doi:10.1186/1475-9276-11-83

6. Anorlu R, Adegbesan M, Adaramewa T. Knowledge of HPV and Cervical Cancer Among HIV-Positive Women in Lagos, Nigeria. 2010.

7. Ezechi OC, Gab-Okafor CV, Ostergren PO, Pettersson KO. Willingness and acceptability of cervical cancer screening among HIV positive Nigerian women. BMC Public Health. 2013;13(1):46. doi:10.1186/1471-2458-13-46

8. Nwabichie CC, Manaf RA, Ismail SB. Factors affecting uptake of cervical cancer screening among african women in Klang Valley, Malaysia. Asian Pac J Cancer Prev. 2018;19(3):825-831.

9. Ncube B, Bey A, Knight J, Bessler P, Jolly PE. Factors associated with the uptake of cervical cancer screening among women in portland, Jamaica. N Am J Med Sci. 2015;7(3):104-113. doi:10.4103/ 1947-2714.153922

10. Ogbonna FS. Knowledge, attitude, and experience of cervical cancer and screening among Sub-saharan African female students in a UK University. Ann Afr Med. 2017;16(1):18-23.

11. Ntekim A Cervical Cancer in Sub Sahara Africa. 2012.

12. Tilahun T, Tulu T, Dechasa W. Knowledge, attitude and practice of cervical cancer screening and associated factors amongst female students at Wollega University, western Ethiopia. BMC Res Notes. 2019;12(1):518. doi:10.1186/s13104-019-4564-x

13. Getachew S, Getachew E, Gizaw M, Ayele W, Addissie A, Kantelhardt EJ. Cervical cancer screening knowledge and barriers among women in Addis Ababa, Ethiopia. PLoS One. 2019;14(5): e0216522. doi:10.1371/journal.pone.0216522

14. Mengesha A, Messele A, Beletew B. Knowledge and attitude towards cervical cancer among reproductive age group women in Gondar town, North West Ethiopia. BMC Public Health. 2020;20(1):209. doi:10.1186/s12889-020-8229-4

15. Saleem A, Bekele A, Fitzpatrick MB, et al. Knowledge and awareness of cervical cancer in Southwestern Ethiopia is lacking: a descriptive analysis. PLoS One. 2019;14(11):e215117. doi:10.1371/journal. pone. 0215117

16. Getahun F, Mazengia F, Abuhay M, Birhanu Z. Comprehensive knowledge about cervical cancer is low among women in Northwest Ethiopia. BMC Cancer. 2013;13(1):2. doi:10.1186/1471-2407-13-2

17. Shiferaw N, Brooks MI, Salvador-Davila G, et al. Knowledge and Awareness of Cervical Cancer among HIV-Infected Women in Ethiopia. Obstet Gynecol Int. 2016;2016:1274734. doi:10.1155/2016/ 1274734

18. Aweke YH, Ayanto SY, Ersado TL. Knowledge, attitude and practice for cervical cancer prevention and control among women of childbearing age in Hossana Town, Hadiya zone, Southern Ethiopia: community-based cross-sectional study. PLoS One. 2017;12(7): e0181415. doi:10.1371/journal.pone.0181415

19. Kangmennaang J, Onyango EO, Luginaah I, Elliott SJ. The next Sub Saharan African epidemic? A case study of the determinants of cervical cancer knowledge and screening in Kenya. Soc Sci Med. 2018;197:203-212. doi:10.1016/j.socscimed.2017.12.013

Cancer Management and Research

Publish your work in this journal

Cancer Management and Research is an international, peer-reviewed open access journal focusing on cancer research and the optimal use of preventative and integrated treatment interventions to achieve improved outcomes, enhanced survival and quality of life for the cancer patient.
20. Okunowo AA, Daramola ES, Soibi-Harry AP, et al. Women's knowledge of cervical cancer and uptake of Pap smear testing and the factors influencing it in a Nigerian tertiary hospital. J Cancer Res Pract. 2018;5(3):105-111. doi:10.1016/j.jcrpr.2018.02.001

21. Al Meer FM, Aseel MT, Al Khalaf J, Al Kuwari MG, Ismail MFS Knowledge, attitude and practices regarding cervical cancer and screening among women visiting primary health care in Qatar. 2011.

22. Mitiku I, Tefera F. Knowledge about cervical cancer and associated factors among 15-49 year old women in Dessie Town, Northeast Ethiopia. PLoS One. 2016;11(9):. doi:10.1371/journal.pone.0163136.

23. Zemedu T. Coverage and factors associated with cervical cancer screening: results from a population-based WHO steps study in Ethiopia. Advan Oncol Res Treatments. 2017.

24. Leung SS, Leung I. Cervical cancer screening: knowledge, health perception and attendance rate among Hong Kong Chinese women. Int $J$ Womens Health. 2010;2:221-228. doi:10.2147/IJWH.S10724

25. Mwaka AD, Orach CG, Were EM, Lyratzopoulos G, Wabinga H, Roland M. Awareness of cervical cancer risk factors and symptoms: cross-sectional community survey in post-conflict northern Uganda. Health Expect. 2016;19(4):854-867. doi:10.1111/hex.12382

26. Sudenga SL, Rositch AF, Otieno WA, Smith JS. Knowledge, attitudes, practices, and perceived risk of cervical cancer among Kenyan women: brief report. Int J Gynecol Cancer. 2013;23(5):895-899. doi:10.1097/IGC.0b013e31828e425c

27. Jassim G, Obeid A, Al Nasheet HA. Knowledge, attitudes, and practices regarding cervical cancer and screening among women visiting primary health care Centres in Bahrain. BMC Public Health. 2018;18(1):128. doi:10.1186/s12889-018-5023-7

28. Toren O, Kerzman H, Koren N, Baron-Epel O. Patients' knowledge regarding medication therapy and the association with health services utilization. Eur J Cardiovasc Nurs. 2006;5(4):311-316. doi:10.1016/ j.ejcnurse.2005.12.001

29. Al-Meer FM, Aseel MT, Al-Khalaf J, Al-Kuwari MG, Ismail MF. Knowledge, attitude and practices regarding cervical cancer and screening among women visiting primary health care in Qatar. Eastern Mediterranean Health Journal $=$ La Revue De Sante De La Mediterranee Orientale $=$ Al-Majallah Al-Sihhiyah Li-Sharq AlMutawassit. 2011;17(11):855-861.

30. Mukama T, Ndejjo R, Musabyimana A, Halage AA, Musoke D. Women's knowledge and attitudes towards cervical cancer prevention: a cross sectional study in Eastern Uganda. BMC Womens Health. 2017;17(1):9. doi:10.1186/s12905-017-0365-3

31. Tekle T, Wolka E, Nega B, Kumma WP, Koyira MM. Knowledge, attitude and practice towards cervical cancer screening among women and associated factors in Hospitals of Wolaita Zone, Southern Ethiopia. Cancer Manag Res. 2020;12:993-1005. doi:10.2147/CMAR.S240364

32. Bansal AB, Pakhare AP, Kapoor N, Mehrotra R, Kokane AM. Knowledge, attitude, and practices related to cervical cancer among adult women: a hospital-based cross-sectional study. J Nat Sci Biol Med. 2015;6(2):324-328. doi:10.4103/0976-9668.159993

33. Tran JH, Mouttapa M, Ichinose TY, Pang J, Ueda D, Tanjasiri SP. Sources of information that promote breast and cervical cancer knowledge and screening among native Hawaiians in Southern California. J Cancer Educ. 2010;25(4):588-594.
The manuscript management system is completely online and includes a very quick and fair peer-review system, which is all easy to use. Visit http://www.dovepress.com/testimonials.php to read real quotes from published authors. 